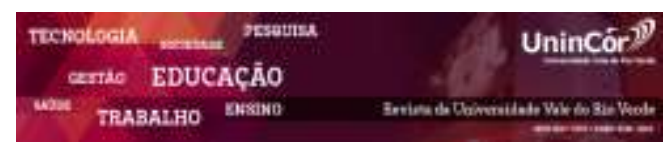

Revista da Universidade Vale do Rio Verde ISSN: 1517-0276 / EISSN: 2236-5362 v. $16 \mid$ n. 2 | Ano 2018

Paulo Henrique Pinho de Oliveira CEFET-RJ paulo.pinho@cefet-rj.br

Isabela Peçanha Gois CEFET-RJ pecanhaisabela@gmail.com

Maria Clara Bravo Goldstein

CEFET-RJ

goldsclara@gmail.com

\section{APLICAÇÃO DO FUNIL DE VENDAS PARA MELHORIA DE ENGAJAMENTO EM UM SVA}

\begin{abstract}
RESUMO
O presente trabalho tem como intuito analisar o comportamento do usuário que utiliza o AppsClub, um serviço de valor agregado, no fluxo de assinatura do portal No Credit. Para isso, foi utilizado a ferramenta de análise de fluxo de vendas, o Funil de Vendas. A análise foi realizada a partir de dados coletados pelas autoras deste trabalho num período de cinco meses - Dezembro de 2017 até Abril de 2018. Dentro disso, serão propostas estratégias para a otimização de vendas do fluxo analisado.
\end{abstract}

Palavras-chave:SVA, Funil de Vendas, Marketing Digital, Marketing Mobile. Ferramenta de Vendas, Vendas.

\section{APLICATION OF SALES FUNNEL TO IMPROVE ENGAGEMENT IN A SVA}

\begin{abstract}
This present work has the intente to analyse the user behavior that utilize the AppsClub, a Value Added Service, in signature stream of the No Credit portal. For this, a sales analysis tool was used, the Sales Funnel. The analyses was made from the data collection performed by the authors of this work in a period of five months December 2017 until April 2018. Within this, strategies will be proposed to optimize sales of the flow analyzed.
\end{abstract}

Keywords:VAS, Sales Funnel, Marketing Digital, Marketing Mobile. Sales

Recebido em: 20/08/2018- Aprovado em: 01/12/2018 - Disponibilizado em: 15/12/2018

\section{Introdução}

Conforme o aumento da utilização de smartphones, muitas empresas observaram esse mercado, e se veem na necessidade de fazer parte. Com isso, esse trabalho foi realizado com o intuito de analisar o fluxo de contratação de um SVA - Serviço de Valor Agregado no canal Nocredit do Serviço AppsClub, a partir da ferramenta de Funil de Vendas.
Para melhor analisar o Funil de Vendas, foi delimitado um período de cinco meses (Dezembro de 2017 até Abril de 2018), essa duração foi importante para que não houvesse sazonalidade nas amostras que foram coletadas. Além disso, foi necessário para melhor compreensão da forma como o usuário realizou a contratação do serviço.

Ao montar os dados coletados dentro do modelo de análise do Funil de Vendas, foi possível compreender a quantidade de usuários 
que estavam sendo retido em cada fase do fluxo, o que, dentro da empresa analisada não foi possível, pois os dados encontram-se em locais distintos impedindo, então, que essa análise seja realizada de forma rápida.

Dentro dessa análise, foram propostas melhorias no fluxo de assinatura do usuário, com a finalidade de aumentar as vendas e por consequência, aumentar o engajamento do usuário no serviço divulgado e analisado.

\subsection{Problema:}

Como se posiciona o funil de vendas do serviço Apps Club dentro do portal Nocredit para uma das principais operadoras de telefonia do brasil.

\subsection{Objetivo:}

Dentro do que foi exposto, esse trabalho tem como objetivo analisar o funil de vendas de uma das principais operadoras de telefonia do Brasil e propor estratégias para otimizar as vendas do serviço Apps Club no canal Nocredit.

\subsection{Delimitação:}

A delimitação utilizada para a realização desse trabalho foi uma das principais operadoras de telefonia do Brasil, utilizando os dados recolhidos pelas autoras durante 5 meses.

O Brasil embarcou no mercado de telefonia móvel em 1990, tendo aparelhos móveis grandes e de custo alto, dessa forma, apenas a classe alta era capaz de pagar para têlos. Hoje, com o avanço da tecnologia há diversos aparelhos celulares que alcançam diversas camadas da pirâmide social, o que dá às operadoras um alcance de público maior, sendo necessário desenvolver diferentes produtos, e assim, se adaptar e obter uma fatia de mercado maior.

\section{O MERCADO DE TELECOM E O SVA}

Serviços de Valor Agregado (SVA) podem ser entendidos como serviços da operadora em geral - excluindo seu core business como cobertura de rede, ligações, mensagem de texto, internet - que agregam valor ao usuário, tais como, serviços de entretenimento e vantagens. Entre os SVAs mais utilizados estão os de toques telefônicos, noticiais, músicas, antivírus, dentre outros.

A Anatel (Agência Nacional de Telecomunicações) define SVA como “Atividade que acrescenta, a um serviço de telecomunicações que lhe dá suporte e com o qual não se confunde novas utilidades relacionadas ao acesso, armazenamento, apresentação, movimentação ou recuperação de informações."

Esses serviços são definidos como $1.0 \mathrm{ou}$ 2.0. Essa definição está atrelada mais à mudança de comportamento dos usuários na WEB do que com as tecnologias que proporcionaram essas mudanças. Os serviços 1.0 têm como característica a navegação e absorção de informação, sendo assim, o usuário normalmente realiza a assinatura e utiliza o serviço via SMS Short Message Service. Já os serviços 2.0 tem por natureza a interação do usuário com alguma plataforma, como aplicativos ou redes sociais.

Apesar de ser um meio recente, e por isso ainda não tão bem regulamentado, no que diz respeito à SVA, por ser um meio ligado à telefonia, tem suas regras e leis que regem esse 
nicho. Isso protege o consumidor de propagandas invasivas, mas, por sua vez restringe e dificulta as estratégias de atingir esse potencial cliente. Essas regulamentações são definidas pela ANATEL e MEF (Mobile Ecosystem Forum) e definem regras quanto à propaganda, abordagem dos usuários, assinatura, cancelamento, dentre outros.

Os serviços de SVAs estão presentes desde o início da utilização de celulares, realizando entretenimento e lazer para o usuário, e com isso, alavancando a receita das operadoras de telefonia. Atualmente, com a utilização da internet e consequentemente o consumo em larga escala de smartphones, houve a necessidade de aumentar o pacote de dados oferecido pelas companhias de telecomunicações e assim houve um aumento na utilização de aplicativos, principalmente OTTs (Over The Top - serviços de áudio e vídeo pela internet, por exemplo, Netflix e iTunes) que passaram a ser concorrentes diretos dos SVAs.

Dentro desse aspecto, as empresas se encontram com dificuldade para além de manter o usuário, fazer com que o mesmo utilize o serviço, ou seja, esteja engajado. Para isso, as empresas que oferecem os Serviços de Valor Agregado, devem estar dispostas a seguir a visão do mercado e tentar, cada vez mais, estar mais próximo do usuário para atender a necessidade do seu cliente.

\subsection{O Que é SVA:}

Uma das maiores mudanças que o mercado de SVA teve, foi um aumento do investimento por parte das empresas de telefonia. Com isso, esse tipo de serviço está com uma maior visibilidade, tanto para os usuários quanto para as operadoras.

A operadora brasileira que está na frente das ofertas de SVAs é a Vivo que é líder do mercado brasileiro com 73 milhões de Clientes móveis, e com um faturamento de $\mathrm{R} \$ 1,9$ bilhão com serviços de valor agregado em 2015, segundo o website (página da internet) da telefônica.

Em 2016, a TIM afirmou ter cerca de 22 milhões de usuários únicos nesse tipo de serviço de acordo com o site da empresa, enquanto a Claro afirma ter mais ou menos 10 produtos no formato de SVA, conforme informações de seu website. Apesar do aumento desse tipo de serviço, as principais operadoras brasileiras afirmam que não estão criando departamentos específicos para esses produtos. Com isso, as empresas de telefonia realizam parcerias com empresas especializadas em SVA.

Durante o segundo semestre de 2016, o mercado de SVA passou por um período de turbulência devido à um alto nível de reclamações dos seus usuários. De acordo com uma pesquisa realizada pelo portal de notícias do mercado mobile, o Mobile Time, em parceria com a OneBox, cerca de $46 \%$ dos usuários afirmam ter algum problema com cobrança indevida relacionado aos serviços de valor agregado.

Dentre os vários motivos que contribuíram para que o mercado de SVA atingisse esse nível de estresse, um dos principais foi o rápido avanço do mercado brasileiro no que tange a expansão do $4 \mathrm{G}$ e a grande utilização de smartphones. Como as operadoras e os parceiros não estavam preparados para esse volume, gerou um desequilíbrio entre os serviços de valor 
agregado e as informações divulgadas para os usuários.

Para evitar uma intervenção regulatória maior e o fim da divulgação desse tipo de serviço, as operadoras tomaram medidas para ter um controle mais completo dos produtos de SVA que estão sendo divulgados.

Uma das providências tomadas foi a utilização de uma plataforma de distribuição de serviço como foi realizado pela Vivo em 2016, que utiliza do SDP (Service Distribution Platform). Nesta plataforma, a operadora consegue ter o controle total de como o cliente foi tarifado e em qual canal foi realizada essa assinatura, e ter, além disso, a confirmação de cancelamento solicitado pelo usuário.

Com esse tipo de tecnologia, as operadoras passaram a ter um controle maior do que está sendo divulgado e assinado por parte do usuário. Com isso, consegue proporcionar uma melhor experiência e fornecer uma assistência maior, caso necessário. Isso foi refletido na diminuição das reclamações em SVA do ano de 2016 para o ano 2017. A tabela 1 abaixo mostra a variação de reclamação de um ano para outro.

Tabela 1 - Quantidade de Reclamações em 2016, 2017 e a variação.

\begin{tabular}{|l|c|c|c|}
\hline Operadora & \multicolumn{2}{|l|}{ Reclamações } \\
de SVA em & \multicolumn{2}{l|}{$\begin{array}{l}\text { Reclamações } \\
\text { de SVA em } \\
2016\end{array}$} & Variação \\
\hline Claro & 12.886 & 14.883 & $15,5 \%$ \\
\hline Oi & 10.336 & 9.127 & $-11,27 \%$ \\
\hline Vivo & 21.413 & 21.003 & $-1,90 \%$ \\
\hline Tim & 26.754 & 22.488 & $-15,90 \%$ \\
\hline Total & 71.389 & 67.427 & $-5,50 \%$ \\
\hline
\end{tabular}

Fonte: Telesintese.com.br - Disponível em 07/05/2018
Com essa maior assistência, as operadoras puderam acompanhar mais de perto a qualidade dos Serviços de Valor Agregado que estavam sendo divulgados.

Dessa forma, as empresas de telefonia observam o tempo de permanência desses usuários na base de assinatura desse serviço, ou seja, que tenham um ciclo de vida maior. Além disso, se esses usuários estão utilizando, de fato, o serviço o qual ele faz parte, demonstra que o engajamento desse serviço está dentro dos parâmetros.

Dentro desse cenário, vemos claramente a importância e a necessidade de aplicação do Marketing de Relacionamento, como Kotler (2017) disse:

"Cada vez mais, as marcas vêm adotando qualidades humanas para atrair consumidores na era centrada no ser humano. [...] Para abordar de forma eficaz ansiedades e desejos, os profissionais de marketing precisam desenvolver o lado humano de suas marcas."

Então, o objetivo do marketing de relacionamento é conquistar e fidelizar clientes, além de fazer com que eles se tornem defensores e divulgadores da marca. E por isso, o foco das operadoras está cada vez mais em satisfazer e gerar valor para seu público, garantindo, assim, um engajamento maior.

\subsection{O Consumidor de SVA:}

Atualmente, o mercado de telecomunicações está em uma batalha constante em um dos maiores desafios de sua trajetória: a grande luta para acompanhar o ritmo insano de proliferação do uso de dados entre os seus 
clientes. A cada dia que se passa, mais aplicativos, dispositivos e recursos estão sendo atualizados. Além disso, esses comportamentos de mercado não vêm mostrando sinais de desaceleração. De acordo com uma pesquisa realizada pela Fundação Getúlio Vargas - São Paulo (FGV-SP) ao final do ano de 2017, o número de celulares atingiu a quantidade de habitantes no Brasil. Isso reflete diretamente na forma como as pessoas utilizam a internet atualmente.

O comportamento e a forma de uso dos telefones celulares avançam de maneira irreversível, determinando novas formas de relacionamento e consumo. Atualmente, para que uma companhia atinja o seu público, é fundamental que esteja presente no mundo digital.

Esse novo tipo de mercado, fez com que o consumidor esteja mais atento ao que a empresa está oferecendo e o que de fato está realizando. Ou seja, o usuário está mais disposto a proclamar seus direitos quando os mesmos não forem atendidos. Com isso, houve um aumento brutal nas reclamações das empresas. O setor que lidera o ranking de reclamações é o de telecomunicações. A tabela 2 demonstra as 10 empresas com mais reclamações no mercado.
Tabela 2 - As 10 empresas com mais reclamações:

\begin{tabular}{|c|l|c|}
\hline Posição & \multicolumn{1}{|c|}{ Empresa } & Total \\
\hline $\mathbf{1}$ & $\begin{array}{l}\text { GRUPO CLARO / NET / } \\
\text { EMBRATEL } \\
\text { MÓVIL) }\end{array}$ & 5.883 \\
\hline $\mathbf{2}$ & GRUPO VIVO/TELEFÔNICA & 3.901 \\
\hline $\mathbf{3}$ & SKY BRASIL SERVIÇOS LTDA. & 2.731 \\
\hline $\mathbf{4}$ & TIM CELULAR S/A & 2.351 \\
\hline $\mathbf{5}$ & $\begin{array}{l}\text { GRUPO PÃO DE AÇÚCAR / } \\
\text { EXTRA / PONTOFRIO.COM / } \\
\text { CASASBAHIA.COM / CASAS } \\
\text { BAHIA / PONTO FRIO }\end{array}$ \\
\hline $\mathbf{6}$ & GRUPO ITAÚ UNIBANCO & 1.830 \\
\hline $\mathbf{7}$ & CAIXA ECONOMICA FEDERAL & 1.595 \\
\hline $\mathbf{8}$ & GRUPO UNIMED & 1.497 \\
\hline $\mathbf{9}$ & GRUPO OI & 1.388 \\
\hline $\mathbf{1 0}$ & GRUPO BRADESCO & 1.171 \\
\hline
\end{tabular}

Fonte: Procon - Disponível em 22/10/2017

Dentro desse cenário, as empresas de telecomunicações estão em um momento delicado. Pois, grande parte de seus clientes realizaram portabilidade, que é quando o usuário altera a operadora sem alterar seu número telefônico, devido à insatisfação do serviço prestado pela empresa em questão. Mudando-se, então, para a concorrente devido às promoções mais atraentes.

Desde 2008, ano em que a portabilidade foi iniciada, mais de 40 milhões de usuários já efetuaram uma migração, de acordo com uma pesquisa realizada pela Associação de Brasileira de Recursos em Telecomunicações - ABR Telecom. O gráfico 1 mostra o aumento da portabilidade de 2008 até 2017. 
Gráfico 1 - Aumento da portabilidade de 2008 até 2017

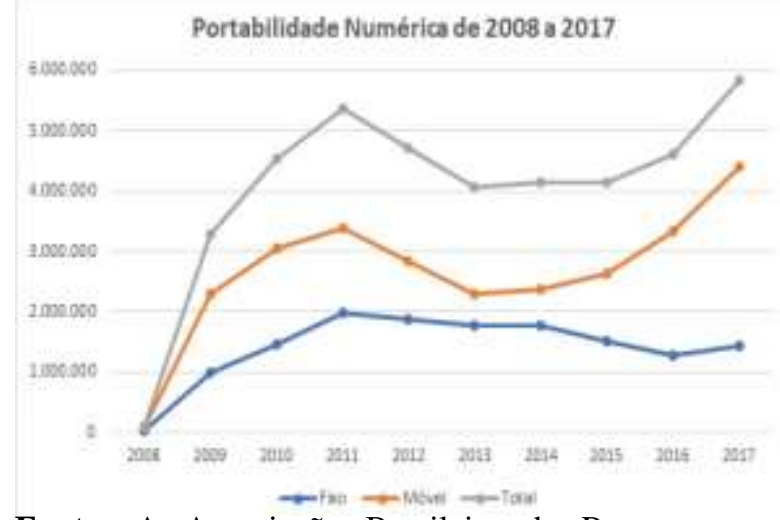

Fonte: A Associação Brasileira de Recursos em Telecomunicações - ABR Telecom. - Disponível em: $24 / 05 / 2018$

Isso demonstra como os usuários não se sentiam totalmente atendidos com as seus planos e operadoras. Para diminuir essa insatisfação do cliente e grande volume de portabilidade, as empresas de telefonia no Brasil estão investindo cada vez mais na tecnologia que utilizam, como rede de fibra ótica e maior cobertura de rede. Além disso, estão melhorando os contratos de prestação de serviços para os clientes, na tentativa de deixar o seu plano mais atraente e satisfatório.

Os planos que estas empresas estão propondo para seus futuros e atuais clientes, além de fornecer mais dados de navegação e de voz, também oferecem os bundles, serviços de valor agregado que vêm embutidos em pacotes oferecidos pelas operadoras. Com isso, ao finalizar a contratação de um plano, os clientes podem usufruir desse serviço já que é um benefício dado pela empresa. A figura 3 mostra a divulgação de um pacote com bundle.
Figura 3 - Divulgação da VIVO do plano Controle com Bundle GoRead

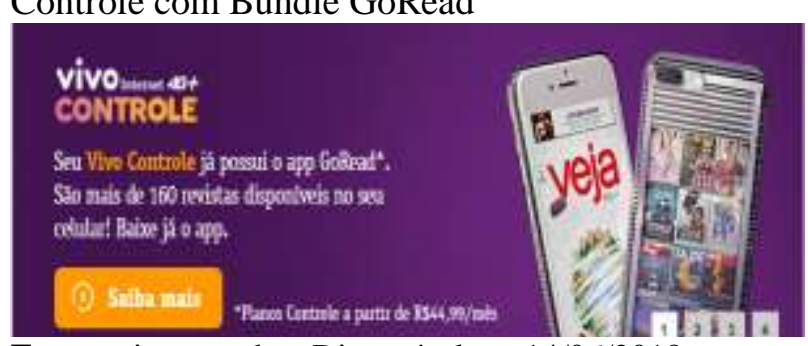

Fonte: vivo.com.br - Disponível em 14/06/2018

Parafraseando Kotler (2011), “Os comerciantes espertos de hoje em dia não vendem produtos, eles vendem pacotes de benefícios. Não vendem somente o valor de compra, mas vendem o valor de uso“. Ou seja, as empresas de telefonia estão buscando mais valor para seus serviços. Dentro desse grande movimento no mercado de telecomunicações, as operadoras estão cada vez mais atentas aos serviços de valor agregado divulgados. Assim, os SVAs não devem ter apenas um bom retorno financeiro, mas também, devem ser algo que o usuário utilize e sinta necessidade de fazer parte. Ou seja, devem ter um bom engajamento de uso do cliente.

Para isso, esse serviço deve ser algo que o usuário sinta vontade de participar, veja necessidade daquele serviço no seu cotidiano e que a oferta tenha um retorno financeiro bom. Um exemplo de SVA com grande participação no mercado é o AppsClub.

\subsection{O Produto - AppsClub:}

De forma a facilitar o entendimento do conceito aplicado, e servir como caso para aplicar futuras estratégias, é selecionado como objeto de estudo deste projeto o serviço AppsClub. O produto funciona com assinatura semanal renovada automaticamente e oferece aplicativos premium liberados para o usuário 
baixar ilimitado e gratuitamente (nas lojas Android e iOS esses aplicativos são pagos individualmente). Criado pela Bemobi Mídia e Entretenimento LTDA, foi lançado pela operadora de Telefonia OI MÓVEL S.A, em 2013. Após, o serviço foi lançado nas outras principais operadoras em 2014, como Vivo, TIM e Claro.

Dentre os aplicativos que são destacados, estão Facetune (aplicativo de fotografia), Fruit Ninja (aplicativo de jogo), Galinha Pintadinha (aplicativo de conteúdo infantil), Runtastic (aplicativo para atividade física), dentre outros. Os aplicativos estão entre os mais baixados em suas categorias.

$\mathrm{O}$ serviço funciona como um clube no qual, ao assinar, o usuário tem direito a um período de degustação, e após esse período é cobrado o valor semanal que varia de acordo com a operadora. Durante o período de atividade da assinatura, o cliente tem acesso ilimitado a todos os aplicativos oferecidos que variam entre jogos, aplicativos de fotografia, saúde, organização financeira, dentre outros. A tabela 3 apresenta alguns dos principais aplicativos disponíveis. Em seguida, a tabela 4 demonstra a tarifação semanal do serviço por operadora.

Tabela 3 - Principais aplicativos do AppsClub

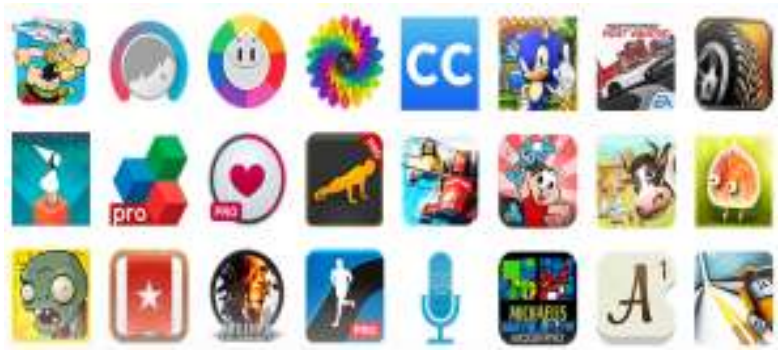

Fonte: http://www.appsclub.com/ - Disponível em $14 / 06 / 2018$
Tabela 4 - Tarifa Semanal e período de degustação do AppsClub por operadora.

\begin{tabular}{|c|c|c|c|c|}
\hline Operadora & Oi & Vivo & Claro & Tim \\
\hline $\begin{array}{c}\text { Período de } \\
\text { degustação } \\
\text { (dias) }\end{array}$ & 7 & 7 & 7 & 7 \\
\hline $\begin{array}{c}\text { Tarifação } \\
\text { semanal }\end{array}$ & $\mathrm{R} \$ 3,99$ & $\mathrm{R} \$ 4,99$ & $\mathrm{R} \$ 4,99$ & $\mathrm{R} \$ 4,19$ \\
\hline
\end{tabular}

Fonte: Elaboração própria, com base em dados da empresa.

A assinatura do serviço pode ser feita via SMS enviando a palavra "APPS" para o Large Account (LA - número de até 5 dígitos usado para fazer a comunicação do produto com o usuário via SMS) do produto, através dos portais, aplicativos ou através dos demais canais de divulgação. Após receber o SMS de confirmação, o cliente já pode usufruir do serviço. Para realizar o cancelamento, o usuário deve enviar a palavra "SAIR" para o mesmo LA. A utilização do serviço se dá por meio da loja WEB mobile ou aplicativo. Por se tratar de um serviço distribuído e divulgado pelas operadoras, o principal acesso se dá pelo celular. A figura 5 demonstra o fluxo de download de um conteúdo.

Figura 5 - Fluxo de download jogo do AppsClub.

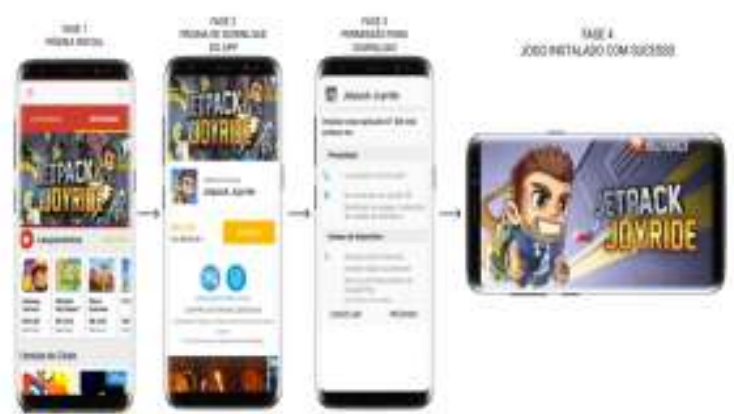

Fonte: As autoras deste trabalho, imagens retiradas de AppsClub.

O AppsClub é um serviço relevante e já consolidado no mundo de SVAs, entretanto, é preciso que se mantenha em constante 
atualização e acompanhando as tendências já que a concorrência no mercado é grande e há outros serviços disponíveis, principalmente nas lojas de aplicativos para Android e iOS, que estão concorrendo com a mesma fatia de mercado.

Como estratégia para ganhar market share frente à concorrência, é preciso além de investir em um bom produto, ter também um olhar mais atento à exposição, divulgar um aplicativo que está de acordo com o público alvo, observar se as estratégias de venda estão sendo efetivas e em quais canais essa propagação está sendo realizada. Com isso, é possível trabalhar para melhorar a forma como o serviço é percebido pelo usuário e tentar alcançar o cliente em potencial.

O AppsClub, é divulgado em canais específicos de divulgação mobile criados junto às operadoras, que permitem alcançar uma base maior de usuários, e assim, agregar mais valor aos seus clientes. Dentro dos principais canais de divulgação, estão: Smart Message, URA e Nocredit.

O Smart Message (ou PUSH notification) é conhecido por ser um canal mais enérgico, já que se trata do disparo de uma mensagem para uma base selecionada, esta é entregue diretamente no aparelho celular através de uma notificação do tipo "pop up" (tipo de janela que se abre na tela), oferecendo aos clientes serviços de valor agregado com apenas um clique. Por ser uma tecnologia baseada no chip (SIM), é compatível com a maioria dos tipos de usuários, além disso, tem um alcance muito maior comparado aos outros meios de divulgação, tornando-se um dos principais canais de aquisição. A figura 6 demonstra um exemplo de Smart Message.
Figura 6 - Exemplo de Smart Message

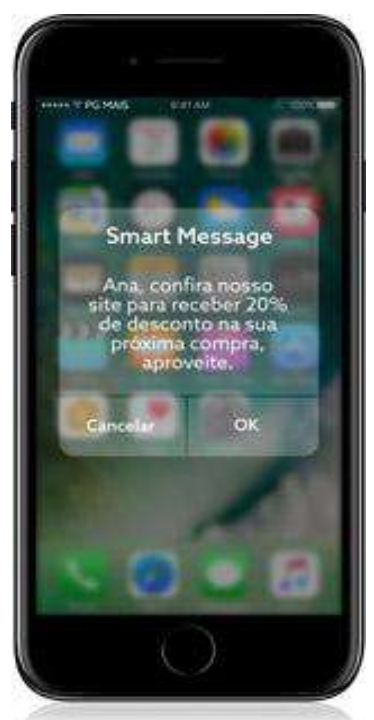

Fonte: Pg Mais - Disponível em 22/11/2017

A URA, por sua vez, é um canal onde os serviços de valor agregado são vendidos através de ligações, seja PULL, quando o usuário liga para URA, ou PUSH, quando o usuário é redirecionado para o canal. $\mathrm{O}$ usuário ouve as gravações de diversos serviços e para assinar, basta digitar um número específico. As maiores partes desses usuários acessam o canal através de números para contatar a operadora, ou são redirecionados para ela por não conter créditos suficientes para realizar uma ligação, por isso, é o segundo canal com mais abrangência. A figura 7 representa um exemplo de URA.

Já o No Credit, é um portal em que o usuário é redirecionado quando está sem crédito e tenta acessar a internet no navegador. Dentro deste portal, são expostos diversos banners (imagens - peças publicitárias) vendendo Serviços de Valor Agregado. Ao clicar, o usuário é levado para a Landing Page (onde encontra mais informações sobre o serviço, realiza a assinatura, e após é redirecionado para o serviço). Esse canal se difere dos outros por possuir mais elementos gráficos, deixando a 
venda mais rica em comunicação. Conforme demonstra a figura 8 .

Figura 7 - Exemplo de No credit

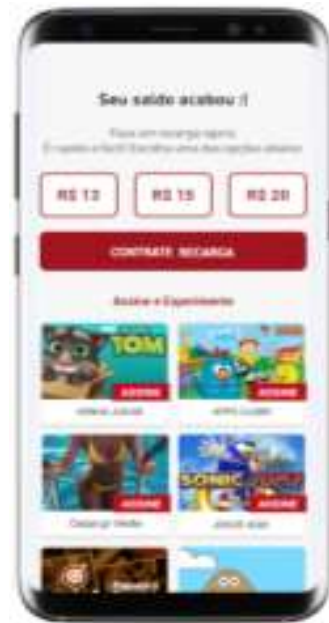

Fonte: Elaboração própria, com base no portal Nocredit.

Diante disso, é percebida a importância de direcionar a divulgação dos SVAs, de forma a aproveitar a base de usuários fornecida pela operadora, e assim, obter uma maior conversão de clientes. Por isso, é determinado como objetivo deste presente trabalho, analisar o funil de vendas de uma das principais operadoras de telefonia do Brasil e propor estratégias para otimizá-lo no serviço AppsClub para o canal Nocredit.

\section{Funil de vendas}

Como aumento do acesso à internet, os consumidores estão mais conectados e mais conscientes de suas ações, e exigências acerca dos conteúdos, serviços e produtos que consomem.

Para se adaptar a esse novo modelo de negócio e não perder o grau de participação no mercado - Market Share, as empresas estão adotando novas estratégias para conquistar os clientes e retê-los em suas bases. O objetivo é fazer com que o cliente se identifique com a marca e utilize o produto, "vestindo a camisa" da empresa. Uma das ferramentas utilizadas para analisar o comportamento do consumidor durante toda a sua jornada de compras, é o Funil de Vendas.

O Funil de Vendas tem como finalidade dar analisar o fluxo de engajamento dos clientes a partir do primeiro acesso do usuário, a partir disso fasear as etapas do caminho de assinatura. Assim, conseguir estabelecer o fluxo da trajetória do usuário até a meta previamente determinada.

Essa tática tem como ideia central que todos os usuários que acessam a página ou site estão no topo do funil, também conhecidos como leads, ou seja, um contato novo que a empresa recebe. Conforme estes forem se conectando com a marca, haverá um avanço pelas demais etapas até a ponta do fluxo. Os clientes que chegam ao final, são considerados os que convertem ou engajam, dependendo de qual será a meta escolhida pela empresa.

Essa estratégia torna-se importante, pois, analisa cada etapa, sendo possível identificar o comportamento do consumidor e entender em qual ponto existe alguma falha ou preciso alterar a tática utilizada. Esse método permite realizar testes para encontrar meios que difundem a melhor a ideia que a marca deseja passar, e assim, atingir o seu público-alvo.

Segundo a Endeavor, no primeiro passo da metodologia do Funil é necessário definir o perfil de usuário que a empresa deseja conquistar. Para isso, é preciso entender a fundo qual a persona que esse consumidor possui, ou seja, a personalidade que o indivíduo representa. Para chegar a esse perfil, é necessário realizar alguns questionamentos: 
- Quem toma a decisão de compra? - Seja no trabalho ou no lar, é importante entender quem toma a decisão de realizar aquela compra.

- Quando o seu cliente prefere comprar? Quais dias ou horários o usuário costuma comprar. É necessário entender também a rotina de compra. Exemplo: Restaurantes self-service tem seus picos de vendas durante o horário de almoço.

- Quanto gasta com produtos com produtos e serviços similares? - Entender qual é a renda que esse cliente possui, e qual o orçamento e até quanto ele está disposto a pagar.

- Onde e qual tipo de conteúdo consomem? O que esse usuário gosta de ouvir, ver e ler.

O objetivo central é definir as características que formam o perfil dos clientes, entender como eles se comportam, o que gostam de fazer, ouvir, como é a sua rotina, quais seus desejos, dentre outros. Entendendo esse comportamento, é possível traçar uma tática focada nesse usuário. Com essa definição, a próxima fase torna-se a delimitar ponta a ponta do funil e determinar quais etapas que esse usuário irá realizar até ter o que deseja.

As etapas variam de acordo com o modelo de negócio, abordagem, produto ou serviço, canal analisado, dentre outros. Não há uma regra definida, o funil deve ser a jornada do cliente e deve incluir desde o processo de criação de consciência do produto ao compartilhamento da experiência do seu cliente com a sua marca. Entretanto, em geral, um funil de vendas possui de 5 a 7 etapas.
O modelo "AIDA", citado pela primeira vez por Elias Elmo Lewis (AID) e mais tarde complementado por Edward Kellogg Strong, com o último estágio (Ação), define de forma sintetizada definem de forma sintetizada as principais fases do funil e defende um ciclo pelo qual as pessoas passam antes de converterem. $\mathrm{O}$ modelo define que os principais estágios para o cliente chegar à compra são: Despertar Atenção, Criar Interesse, Desejo e Ação, como mostra a figura 9.

Figura 9 - Funil AIDA
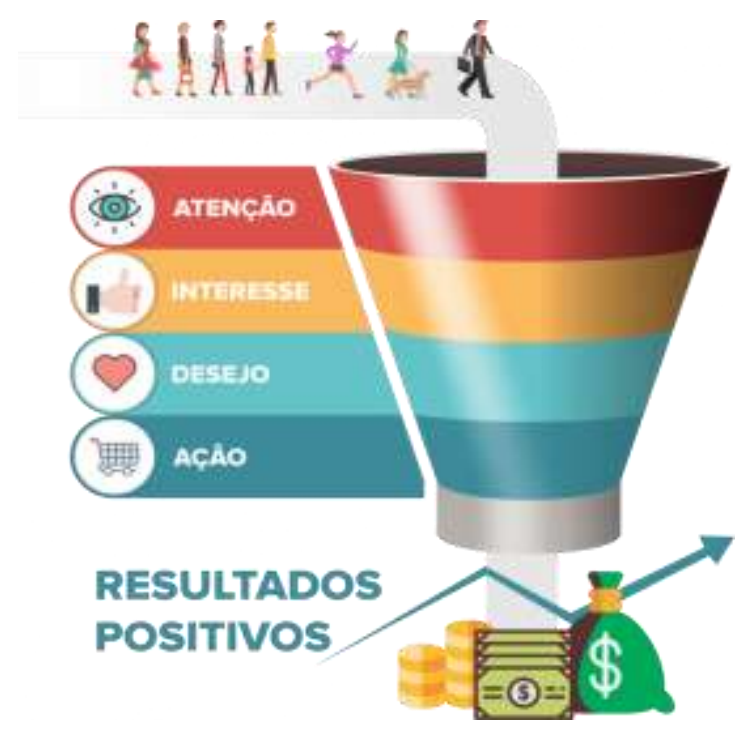

Fonte:https://www.grupodinamica.com.br/2018/01/11 /empresas-devem-fazer-stories-o-metodo-aida-teresponde/- Disponível em: 14/06/2018

- Atenção: Esse é o primeiro contato do potencial cliente com o produto ou serviço ou empresa. É nesse momento que se deve atraí-lo para despertar um possível interesse, caso contrário não haverá possibilidade para os demais passos. A combinação de cores, e frases de efeito são bem-vindas nessa etapa.

- Interesse: Conseguido a atenção para o produto exposto, é a hora de gerar interesse com uma estratégia adequada à persona e 
com conteúdo de qualidade. É o momento de se aproximar, com uma abordagem próxima que busque criar ou conversar com a necessidade do possível cliente.

- Desejo: Essa etapa é fundamental, pois, é nela que é despertado o desejo do usuário em adquirir o serviço ou produto exposto. É o momento em que é apresentado ao usuário as vantagens e qualidades do que é mostrado, buscando torná-lo irresistível à compra e extremamente necessário.

- Ação: É na última etapa do funil que a conversão é concretizada. Nela, é importante que hajam garantias que reforcem o que o usuário já está desejando fazer para, dessa forma, assegurar o sucesso na conversão.

Há diversos modelos que defendem um funil com etapas ou sub-etapas mais detalhadas, estes irão variar de acordo com o produto/serviço e canal em que está sendo divulgado, pois o canal definirá como o cliente acessa o serviço. Entretanto, o modelo AIDA aborda as principais fases, podendo, assim, ser adaptado a qualquer canal e serviço.

Um exemplo prático seria o de uma propaganda de um site de viagens. Se, hipoteticamente, a companhia "VIAJE MAIS" realizar uma anuncio em redes sociais sobre uma promoção nos seus pacotes de viagem, a primeira etapa do seu funil seria a quantidade de pessoas que ficaram interessadas e clicaram na propaganda. A segunda etapa, seriam quantos futuros clientes entraram no site e deixaram seu e-mail para contato. A terceira etapa, seria quando esse usuário interessado realiza um contato com a empresa. A quarta etapa, seria quantos usuários fecharam o pacote de viagem.

Dessa forma, é possível perceber como é mapeado o fluxo do usuário desde o primeiro contato com o produto, passando pelas demais fases de interesse, desejo, e por último, concluindo o objetivo do funil, realizando a ação final. Por isso, é importante analisar cada etapa para entender o impacto que cada uma traz para o cliente em potencial, e como elas influenciam para no cumprimento da meta estipulada.

\subsection{O Funil de Vendas do AppsClub}

A ferramenta do funil de vendas pode ser aplicada em qualquer tipo de mercado, inclusive o mobile. Conforme citado no capítulo dois, o AppsClub é um serviço de valor agregado já consolidado no meio. Esse aplicativo tem como foco jogos e apps premium onde o usuário pode baixar ilimitado e sem gastar seus dados móveis.

Um dos grandes desafios do mundo digital, é manter o usuário utilizando o serviço pois é percebido que quanto maior o engajamento na mídia, maior é o retorno financeiro desse usuário. Dessa forma, é sempre importante criar novas maneiras de resgatar esse usuário. Com essa perspectiva, no portal No credit existe uma grande possibilidade para realizar esse movimento.

Como muitos dos serviços que existem hoje no meio mobile e digital, o AppsClub vêm enfrentando problemas de engajamento no seu serviço, ou seja, muitos dos usuários que fazem parte do clube não utilizam o serviço de maneira completa. Um dos principais canais massivos que apresentam baixo engajamento é o No Credit. 
O No Credit, já mencionado, é o canal onde o usuário, sem crédito e sem dados, tenta realizar acesso a algum site e é redirecionado para o portal. Nele, há a exposição do produto com imagens e o usuário passa por diversas fases até chegar às etapas finais de compra e engajamento, como mostra a figura 10 .

Figura 10 - Fluxo de Engajamento do AppsClub no No Credit

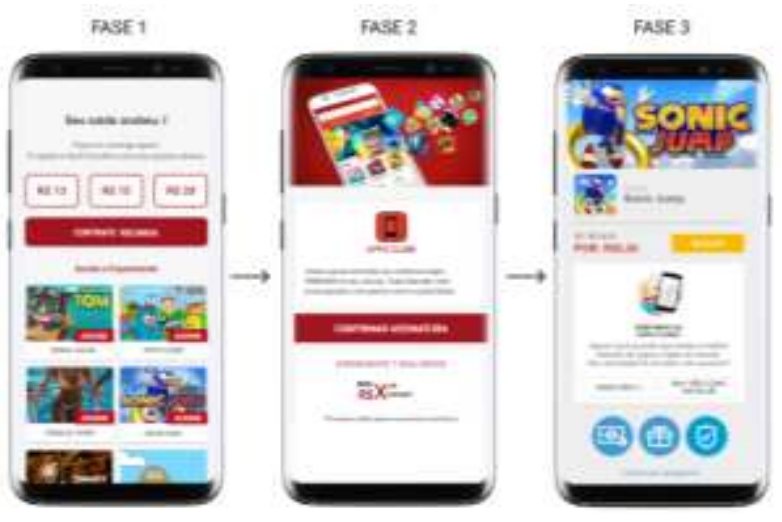

Fonte: Elaboração própria, com base no serviço AppsClub no portal Nocredit

$\mathrm{Na}$ etapa um, vista na figura acima, o usuário tem o primeiro contato com o serviço ao acessar o portal - os banners de divulgação. Cada vez que um usuário os visualiza, é contada uma impressão. Com o interesse do cliente em adquirir ou ter mais informações sobre o produto, há o clique no banner que leva diretamente para a segunda etapa.

Na etapa dois, há a Landing Page, uma página focada em transformar esse lead em cliente. Nela há informações do produto, como título da oferta, uma descrição atrativa do serviço e um call to action - todo botão, imagem ou texto que incentiva o usuário a realizar uma ação. Ao clicar nesse botão, o usuário é assinado no AppsClub.

Para ter uma análise melhor das imagens e serviços que estão sendo divulgados no portal, é realizado o cálculo de conversão de assinatura.
Esse número vem da quantidade de assinaturas provenientes do banner, dividido pela quantidade de vezes que essa figura aparece no portal Impressão do banner.

Após realizada a assinatura do serviço, o usuário faz o download - transferência de um ou mais arquivos de um servidor remoto para um dispositivo local, da mídia (aplicativo) divulgado no banner, finalizando, assim a terceira e última etapa do fluxo do portal. O download da mídia é contabilizado como engajamento do serviço.

Uma prática comum no mercado de SVA, é realizar análises pontuais em seus serviços com KPI's (Key Performance Indicator em português "Indicador Chave de Desempenho", métricas utilizadas para medir o desempenho de processos de uma empresa), como conversões de assinatura e CTR (Click Through Rate - Quantidade de cliques divididos pela quantidade de visualizações do banner). Esse tipo de análise é individual, olhando apenas para partes do fluxo e deixando de observar a experiência total do usuário.

Com isso, não é possível identificar o ponto de maior retenção dos usuários, ou seja, não há como saber em qual ponto o usuário se desinteressa ou interessa pelo produto que está sendo divulgado. Para ter uma melhor compreensão daquilo que o usuário está sentindo, é necessário realizar uma análise ponta-a-ponta do fluxo de assinatura do serviço e, assim, efetuar possíveis mudanças para melhor atender esse cliente.

Observando essa demanda essencial e que não havia sido explorada, é proposto analisar o funil de vendas do serviço de AppsClub no portal Nocredit em uma das principais operadoras de telefonia do Brasil (que não será 
citada por motivo de sigilo contratual). O método será de observação direta e análise de dados, sendo assim, viável, em caso de necessidade, propor essas soluções, visando despertar a atração desse potencial cliente para convertê-lo. Para garantir a análise simples, porém, completa, será estudado o período de 5 meses, que compreende Dezembro de 2017 à Abril de 2018.

Atualmente, os dados das etapas do fluxo de assinatura do usuário citados acima, estão dispostos conforme demonstrado na Tabela 5 . Dentro dessa estrutura, não é possível observar de, maneira clara, as etapas que o consumidor percorre e quais delas mais influenciam o usuário a chegar na etapa final do fluxo.

Para que seja possível analisar os dados do portal sem revelar informações sigilosas da operadora escolhida, os números expostos foram alterados em valores absolutos, porém mantendo a proporção para que a análise seja feita corretamente.

Tabela 5 - Disposição atual dos dados do Fluxo de Assinatura do usuário do Canal Nocredit no serviço AppsClub

\begin{tabular}{|l|l|l|l|l|}
\hline Mês & Impressão & Cliques & Assinatura & Engajamento \\
\hline Dezembro & 60.053 & 709 & 82 & 50 \\
\hline Janeiro & 65.182 & 604 & 102 & 64 \\
\hline Fevereiro & 42.202 & 482 & 66 & 44 \\
\hline Março & 53.563 & 516 & 69 & 33 \\
\hline Abril & 48.143 & 486 & 85 & 36 \\
\hline Total & 269.143 & 2.797 & 404 & 227 \\
\hline
\end{tabular}

Fonte: Elaboração própria com base em dados reais, valores alterados por sigilo.

Por esse motivo, os dados de cada etapa do fluxo de assinatura do usuário, foram dispostos conforme a ferramenta de análise do fluxo de vendas - o Funil de Vendas. Como demonstra a figura 11.
Figura 11 - O Funil de vendas de AppsClub do período de Dezembro de 2017 até Abril de 2018

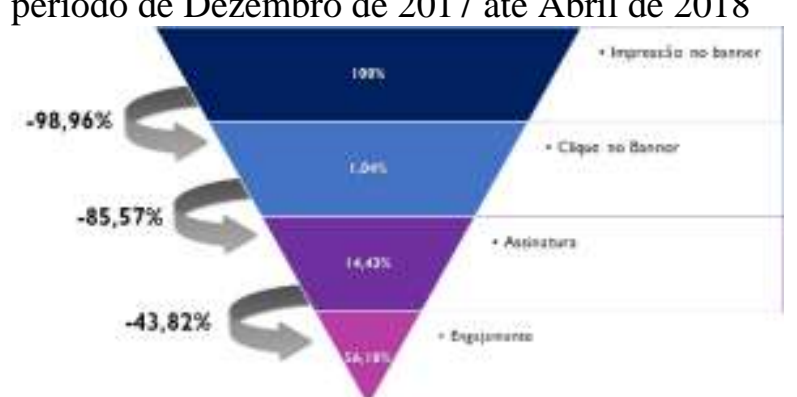

Fonte: Elaboração própria, com base em dados extraídos do serviço AppsClub no portal Nocredit.

Nota-se, como em todo funil de vendas, a discrepância desde a primeira etapa (impressão) até a última (engajamento), entretanto, buscando aumentar os usuários assinantes e engajados no serviço, e consequentemente, a receita do mesmo, é necessário que haja uma diminuição na disparidade entre as etapas. Ou seja, diminuir a evasão de usuários de cada estágio, assim, aumentando a conversão final.

Analisando a retenção de cada fase é percebido que a parte que mais retém pessoas é "Impressões no banner", porém ela reflete a quantidade de vezes que a imagem é mostrada para o usuário, algo que não depende da interação dele. É considerado, assim, como foco estratégico o segundo maior estágio com contenção de pessoas, os "Cliques no banner", etapa que depende diretamente da interação do usuário.

Com a diferença percentual da segunda para a terceira etapa (assinatura) é perceptível o caminho que o usuário percorre e onde o interesse dele diminui. $\mathrm{O}$ cliente ao acessar o portal, clica no banner, porém desiste de realizar a assinatura e retorna para a página anterior ou deixa o portal. Nesse ponto, é preciso estudar o fluxo e os elementos que o pertencem para entender o que desmotivou esse cliente ou o que pode ser implementado que o motivará. 
Além disso, como dito, a tendência de mercado que as operadoras vêm seguindo e aplicando, é adotar um olhar mais atento ao engajamento dos Serviços de Valor Agregado. Sendo assim, é possível medir a qualidade do produto para o cliente. Diante disso, é primordial uma dedicação maior ao envolvimento do usuário no serviço do AppsClub.

\subsection{Soluções para melhoria:}

Dentro deste conceito de Funil de Vendas pré-estabelecido no capítulo anterior, este trabalho de conclusão de curso tem o propósito de propor soluções para a melhoria desta ferramenta de análise, objetivando reter menos pessoas em cada fase da ferramenta, e assim, aumentar a conversão final para fazer com que a meta seja concluída com sucesso.

\subsubsection{Carrossel segmentado}

Analisando a ferramenta de análise do fluxo de vendas implementado no canal Nocredit para o serviço AppsClub, é perceptível que a maior retenção de pessoas se encontra na etapa de impressões do portal (a primeira). A impressão do banner é a quantidade de vezes que o banner foi impresso na página, não dependendo da interação do usuário, é uma etapa fundamental que demanda atualizações de conteúdos constantes. Sendo algo frequente, é preciso analisar os resultados dessas atualizações, e assim, observar como o usuário reage. Entretanto, sendo esta uma tarefa recorrente e padrão desse tipo de canal, é definido como a etapa de maior retenção a segunda.

Com essa visão, é considerada a segunda etapa como a que mais retém pessoas, já que entre o clique no banner e a quantidade de assinatura no serviço, perde-se cerca de $86 \%$ dos usuários. Ou seja, o usuário clica no banner e vai para a página de assinatura, porém não contrata e retorna para a página inicial do portal NoCredit. A figura 14 ressalta essa perda.

Figura 14 - Diferença entre a etapa do "Clique no banner" e "Assinatura".

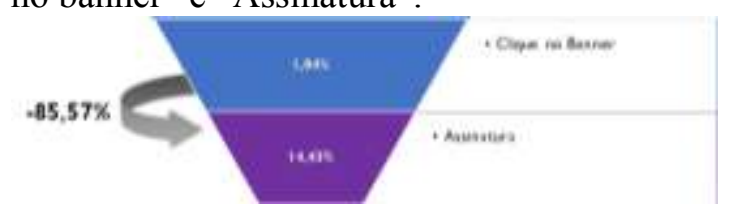

Fonte: Elaboração própria com base no Funil de Vendas do serviço AppsClub no portal Nocredit.

Para tanto, é proposto que, quando esse usuário retorne para a home (página inicial) do portal, ele seja interceptado por um pop up de recomendação, isto é, uma pequena tela que surge sem interferir na navegação do usuário. Esse pop up teria outros jogos que seguem a mesma linha do jogo divulgado no banner clicado anteriormente. O objetivo é aproveitar o interesse do potencial cliente na categoria de jogos anunciados e ofertar outros semelhantes com a maior probabilidade de fazê-lo desejá-los e assim, contratar. A figura 15 expõe o modelo proposto.

Figura 15 - Exemplo de carrossel segmentado.

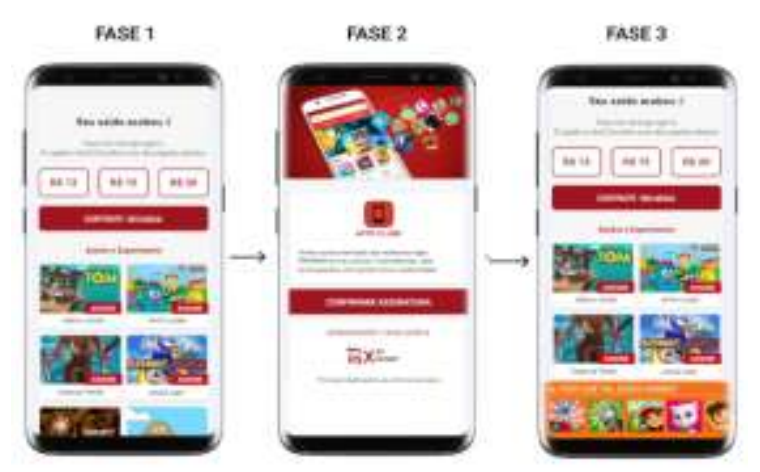

Fonte: Elaboração própria, com base no serviço AppsClub no portal Nocredit. 
Com essa proposta sendo efetivada, uma das maiores lacunas no funil de vendas do portal Nocredit para o serviço AppsClub, seria diminuído. Pois, o cliente perdido no fluxo atual, será reconquistado ao sugerir para ele produtos mais segmentados de forma personalizada, estando assim, mais próximo do usuário.

\subsubsection{Gamificação de Landing Pages}

Como o mundo cada vez mais conectado, e com novidades surgindo a cada momento, fica cada vez mais difícil captar a atenção dos indivíduos. Esse desafio se estende principalmente à área de marketing, sendo necessário desenvolver novas estratégias para despertar mais interesse desses possíveis clientes.

Dentro desse ambiente, novas estratégias são montadas para conquistar esse potencial consumidor. Um desses métodos é a Gamificação, segundo Reis (2011) pode ser definido como “(...) a tendência a se atribuir características próprias da mecânica dos jogos, como pontuação, nivelamentos e recompensas por desempenho às atividades do cotidiano que não possuem caráter de jogo explícito."

Ou seja, entende-se como táticas que promovem o contato entre indivíduos ou companhias, oferecendo recompensas que incentivem o envolvimento de forma criativa, assim, despertando a competitividade no ser humano. A figura 12 representa a gamificação de aprendizagem de um novo idioma através do aplicativo "Duolingo".
Figura 12 - Representação de Gamificação do "Duolingo"

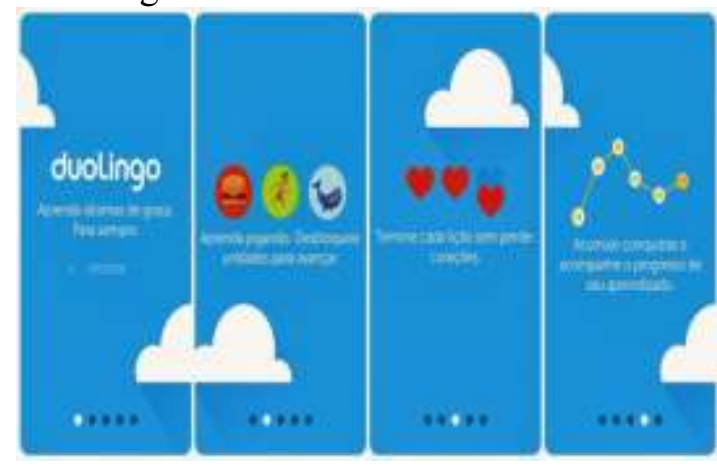

Fonte:http://ticem360.blogspot.com/2016/02/gamifica cao.html - Disponível em 08/06/2018

Um jogo facilmente desperta a competição das pessoas, e com isso, gera interesse do usuário. Diante deste conceito, por que não o utilizar para instigar o consumidor $\mathrm{e}$ guiá-lo para a assinatura do serviço através de um jogo? A introdução possibilita uma primeira experiência mais atraente e tentadora, além de ampliar as chances de mantê-los por perto para concluir uma pesquisa ou explorar o website com mais detalhes.

Dentro desse conceito, é possível observar mais uma proposta para melhoria do problema de engajamento que o serviço de AppsClub vem enfrentando. Para isso, é proposto uma landing page que contenha um jogo rápido e simples, que capture a atenção do usuário durante um tempo, e logo após, o redirecione para realizar a contratação, gerando engajamento no serviço, com a proposta de "continue jogando". A figura 13 demonstra uma simulação da ideia proposta. 
Figura 13 - Exemplo de gamificação no canal Nocredit

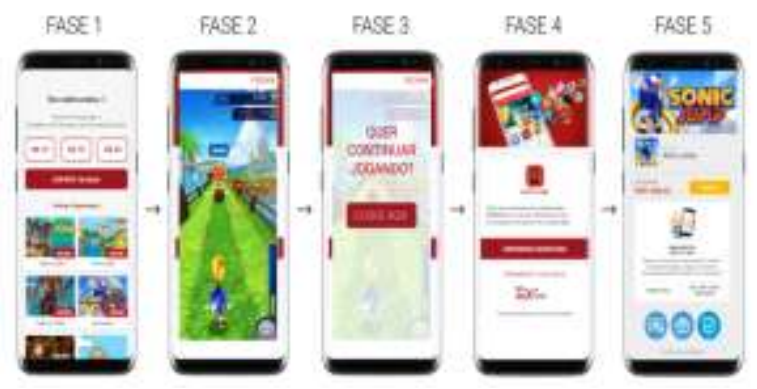

Fonte: Elaboração própria, com base no serviço AppsClub no canal Nocredit

\subsubsection{Mapa de Calor ou "HeatMap":}

Os mapas de calor são ferramentas muito utilizadas para melhorar a experiência do usuário dentro de um website. Nele é possível saber quais elementos do site o usuário teve mais interação. Essas interações podem ser cliques ou movimento do mouse (cursor) ou rolagem de página. Com esse tipo de análise, sabe-se o suficiente para entender o que deve ser repensado no fluxo de uso do cliente. A figura 12 representa um exemplo de HeatMap.

Figura 12 - Exemplo de HeatMap.

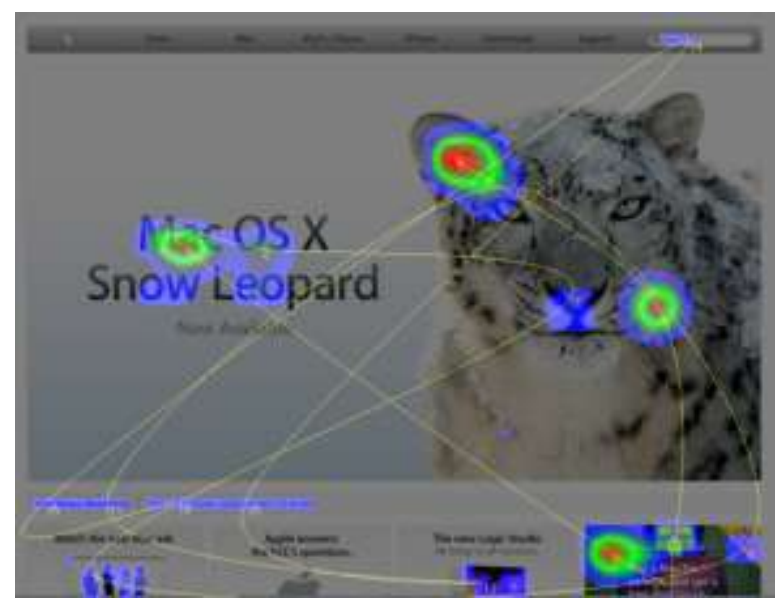

Fonte: http://fuzeseo.co/better-digital-marketerusing-heatmaps/ - Disponível em 08/06/2018

O mapa de calor revela áreas em que o usuário tem mais interação ou são ignoradas, dependendo da cor do mapa. Quanto mais avermelhado, mais o usuário teve interesse na área. Ao entender isso, verifica-se a possibilidade de reestruturar o website da maneira que mais atraia e encante o consumidor.

Deste modo, percebe-se a importância do uso dessa estratégia e como pode ser útil para detectar possíveis problemas e melhorias no website. Portanto, essa ferramenta pode ser aplicada ao serviço em questão, o AppsClub. Tendo como objetivo, identificar as regiões da página que mais atraem o usuário, e dessa forma, reposicionar os elementos, fazendo com que fique à vista itens mais interessantes e que despertem o desejo de compra nesse indivíduo e assim, aumentar a conversão do serviço.

\section{CONSIDERAÇÕES FINAIS}

A primeira etapa deste trabalho foi entender a história do marketing e as suas principais fases, dentre elas estão: Era da Produção, onde o foco era apenas em vender um bom produto; Era das Vendas, com uma preocupação em "vender a qualquer custo"; Era do Marketing, no qual os desejos de consumidor passaram a ser uma diretriz de mercado; e finalmente, na Era do Relacionamento, em que é dado maior importância ao feedback dentro do processo de compra e pós-venda.

Nota-se então, o surgimento de uma nova tendência que foi impulsionada pelo advento da tecnologia, crescimento da internet e o desenvolvimento de smartphones. A criação de um novo marketing: O Marketing Digital. Nele, o mercado encontra-se mais focado em atender as necessidades de seus usuários e potenciais clientes, por meio de pelo menos uma plataforma Digital.

Buscando atender a grande demanda de uso de smartphones, surgiu uma nova vertente no 
mercado digital; O Marketing Mobile. Nessa nova categoria, estratégias são pensadas para atender a esse público vindo a tona a ideia de "Mobile First"(dispositivos móveis primeiro). Com isso, as operadoras de telefonia vislumbraram uma oportunidade de negócio: A criação de Serviços de Valores Agregados (Serviços pagos de entretenimento ou vantagens).

A segunda etapa deste trabalho foi constituída em estudar e entender o mercado de SVA e a maneira como o usuário se comporta diante desse tipo de serviço. Notou-se que as empresas de telefonia brasileiras estão a cada dia mais investido em serviços com qualidade e que tenham valor para o cliente, já que, o consumo de SMS e voz vêm decrescendo com o passar dos anos. Como forma de divulgação, as operadoras optaram por novos tipos de canais, dentre eles: PUSH, URA e Nocredit.

Com o objeto de analisar o funil de vendas estudado, foi selecionado o fluxo de assinatura do serviço AppsClub no portal Nocredit de Dezembro de 2017 até Abril de 2018. Com esses dados, foi possível propor uma estratégia de Funil de Vendas para melhor analisar o produto como um todo. O Funil de Vendas é uma análise de fluxo de vendas que tem como finalidade dar suporte a trajetória de compra dos clientes em potencial, por meio de um conjunto de fases e estímulos.

Notou-se, no funil estudado, a discrepância da primeira à última etapa $\mathrm{e}$, consequentemente, a grande retenção de usuários em cada fase, sendo elas: impressão do banner, clique no banner, assinatura no serviço e engajamento (download do aplicativo divulgado).
Posto isso, a última etapa do trabalho constituiu-se em propor possíveis soluções para a melhoria do Funil de Vendas de SVA, as quais estivessem de acordo com as empresas de telefonia, a política de boas práticas do mercado e de acordo com as normas regidas pela Agência Nacional de Telecomunicações (ANATEL). Além disso, prezando pela melhor conversão do serviço e o mais adequado fluxo para o usuário.

A primeira proposta foi o Carrossel Segmentado. Com o objetivo de diminuir a contenção na segunda maior etapa que mais retém usuários, o carrossel resume-se por um pop up de recomendação para o usuário que foi até a página de assinatura, contudo, não a realizou retornando para home do portal Nocredit. Nesse pop up serão exibidos jogos similares aos divulgados no banner clicado anteriormente, o propósito é explorar o interesse do potencial cliente na categoria anunciada.

Já na segunda proposta, foi sugerido a Gamificação das Landing Pages utilizadas. A gamificação consiste em táticas que propiciam proximidade entre os indivíduos ou empresas oferecendo gratificações que estimulem o comprometimento de forma criativa. O objetivo é atrair e instigar o consumidor, assim, sendo possível encaminhá-lo para a contratação do serviço.

Dessa forma, foi levantada a ideia da criação de uma Landing Page no portal, que contenha um pequeno jogo. Com isso, capturando a atenção do usuário, redirecionandoo para a assinatura e por consequência, gerar engajamento no serviço, com a proposta de "continue jogando".

Finalmente, a terceira e última proposta, foi realizar um Mapa de Calor em todo fluxo de 
assinatura do usuário, sendo possível assim saber quais áreas do website o usuário teve mais interação. Dessa forma, reposicionar os elementos, fazendo com que fique nas áreas mais acessadas itens de interesse, provocando desejo de compra do usuário.

Dentro do estudo realizado, observando a disparidade de cada etapa no funil de vendas analisado, espera-se que diante disso as empresas possam observar o engajamento dos clientes de seus serviços nos canais de venda, e que as sugestões apresentadas possam colaborar para otimizar os resultados da empresa.

\section{REFERÊNCIAS}

ADOLPHO, Conrado. Os 8 Ps do Marketing Digital: o Seu Guia Estratégico de

Marketing Digital. São Paulo: Novatec, 2011.

ANATEL - Seção: Glossário. Disponível em: 〈http://www.anatel.gov.br/legislacao/component> Acesso em: 18/10/2017

\section{ASSOCIAÇÃO BRASILEIRA DE RECURSOS EM TELECOMUNICAÇÕES - Seções: Notícias. Disponível em <https://www.abrtelecom.com.br $>$ Acesso em 24/05/2018}

AGENDOR.BLOG - Seções: Estratégias de Venda. Disponível em <https://www.agendor.com.br $>$ Acesso em $30 / 05 / 2018$

APPSCLUBE - Seção: Home. Dispononível em <http://www.appsclub.com/> Acesso em 14/06/2018

BEMOBI - Seção: Home. Disponível em <https://www.bemobi.com.br > Acesso em: $15 / 05 / 2018$

CALAZANS, Paula Medina de. A percepção dos usuários de smartphone em relação ao mobile marketing. Dissertação (Mestrado). Universidade Federal do Rio de Janeiro, COPPEAD de Administração, Programa de Pós-Graduação em Administração, 2014.

CLARO - Seção: Relatórios Financeiros. Disponível em <http://www.claro.com.br/claropar/> Acesso em: $19 / 11 / 2017$

CVA SOLUTION - Seção: Serviços. Disponível em <http://cvasolutions.com.br> Acesso em: 16/10/2017
DATAGAME - Seção: Home. Disponível em <https://datagame.io/using-a-datagame-as-a-landingpage/ > Acesso em: 09/06/2018

GRUPO DINÂMICA - Seção: Blog. Disponível em <https://www.grupodinamica.com.br/2018/01/11/emp resas-devem-fazer-stories-o-metodo-aida-teresponde/> Acesso em: 11/01/2018

GSMA. The Mobile Economy 2014. Disponível em: $<$ http://latam.gsmamobileeconomy.com/ME_LatinAm erica RF WebSpreads 03.pdf >. Acesso em: $27 / 01 / 2018$

IBGE - Seção: Estatísticas. Disponível em <https://www.ibge.gov.br> Acesso em: 15/05/2018

KOTLER, Philip. Marketing 4.0 - do tradicional ao digital. Sextante. New Jersey: John Wiley \& Sons, Inc., 2017.

LAS CASAS, Alexandre Luzzi. Administração de marketing: conceitos, planejamento e aplicações à realidade brasileira. São Paulo: Atlas, 2006.

MARKETING DE CONTEÚDO - Seção: Marketing Digital. Disponível em <https://marketingdeconteudo.com> Acesso em: $01 / 05 / 2018$

MARTIN, Chuck. Mobile Marketing: A Terceira Tela. Como estar em contato com seus clientes através de Smartphones, Tablets e outros dispositivos móveis. Mbooks, 2013.

MINHA OPERADORA - Seção: Notícias. Disponível em $<$ https://www.minhaoperadora.com.br $>$ Acesso em $24 / 05 / 2018$

MOBILE TIME - Seção: News, "Teles tomam ações para reduzir reclamações com SVAs". Disponível em $<$ http://www.mobiletime.com.br $>$ Acesso em $14 / 12 / 2017$

NOVA ESCOLA DE MARKETING - Seção: Comportamento do Consumidor Digital. Disponível em $\langle$ https://novaescolademarketing.com.br $>$ Acesso em: $15 / 05 / 2018$

O GRANDE VENDEDOR, A Era do Marketing de Relacionamento. 13 de Abril de 2015. Disponível em: <www.ograndevendedor.com> Acesso em: $16 / 10 / 2017$

OPINION BOX - Seção: Resultados de Pesquisa. Disponível em <http://blog.opinionbox.com $>$ Acesso em: $16 / 10 / 2017$

PG MAIS - Seção: Canais de Comunicação. Disponível em <http://pgmais.com.br > Acesso em: 22/11/2017 
PROCON - Seção: Pesquisa. Disponível em:

http://www.procon.sp.gov.br/pdf/TEL_MOVEL_2010

.pdf> Acesso em: 22/10/2017

PROPMARK - Seção: Digital. Disponível em

<http://propmark.com.br> Acesso em: 15/05/2018

RECLAME AQUI - Seção: Ranking. Disponível em: <https://www.reclameaqui.com.br> 12/04/2018

SAPIENS SOLUTIONS - Seção: Conteúdo.

Disponível em: <http://sapiensolutions.com.br/mapa-

de-calor-heatmap/> 08/06/2018

TELECO - Seção: Telefonia Móvel. Disponível em: <http://www.teleco.com.br> Acesso em: 16/10/2017

TELEFÔNICA - Seção: Acionistas e Investidores. Disponível em 〈http://www.telefonica.com.br> Acesso em: 19/11/2017

TELESÍNTESE - Seção: Notícias. Disponível em $<$ http://www.telesintese.com.br > Acesso em $22 / 05 / 2018$

TICEM 360, Seção: Home. Disponível em <http://ticem360.blogspot.com/2016/02/gamificacao.h $\underline{\text { tml }}>$ Acesso em 08/06/2018

TIM - Seção: Informações Financeiras. Disponível em <http://ri.tim.com.br> Acesso em: 19/11/2017

VIVO - Seção: Home. Disponível em <http://www.vivo.com.br> Acesso em: 14/06/2018

\section{Paulo Henrique Pinho de Oliveira}

Mestre e professor do curso de graduação em administração no CEFET-RJ.

\section{Isabela Peçanha Gois}

Aluna do curso de graduação em administração no CEFET-RJ

Maria Clara Bravo Goldstein

Aluna do curso de graduação em administração no CEFET-RJ 